\title{
Dursunbey İlçesi'nin Rekreasyon Alanlarına İlişkin Kullanıcı Görüşlerinin Değerlendirilmesi
}

\author{
Figen ALTINER ${ }^{1 *}$, Mehmet AKÇA ${ }^{1}$, Doğan AKDEMIR ${ }^{1}$ \\ ${ }^{1}$ Balıkesir Üniversitesi Dursunbey Meslek Yüksekokulu, Dursunbey, BALIKESIR.
}

\section{Öz}

Teknolojik ilerlemeler, sanayileşme, çarpık kentleşme, aşırı nüfus artışı, yoğun iş temposu gibi nedenlerle insanların doğal yaşama olan isteğini gün geçtikçe arttırmakta, kentlerde ve kent çevrelerinde bulunan rekreasyon alanları, insanların dinlenme eğlenme ve birlikte zaman geçirme ihtiyaçlarını karşılamaktadır. Bu çalışmada Dursunbey ilçesinde bulunan rekreasyon alanlarının niteliksel ve niceliksel olarak incelenmesi amaçlanmıştır. Çalışma alanı olarak Dursunbey İlçesi’nin seçilme sebebi doğal ve kültürel özellikler bakımından oldukça zengin olmasıdır. Yöntem olarak Dursunbey ilçesi merkezinde 76'sı kadın 142'si erkek olmak üzere toplam 218 kişiye anket uygulanmıştır. Anket sonuçlarına göre rekreasyon alanlarına, katılımcıların \%37.6'sı haftalık, \%39'u ise aylık periyotlarla gittiği ve gitme amaçlarının en çok eğlenme olduğu ortaya çıkmıştır. Katılımcıların \%73.8 i rekreasyon alanlarının sayıca eksik olduğunu ifade etmiştir. Mevcut rekreasyon alanlarında karşılaşılan olumsuzluklar değerlendirildiğinde, katılımcıların \%26.8'i gürültü, \%18.9'u güvenlik \%5,'i hava kirliliği ve trafik yoğunluğu, geri kalan \%43.6'sı ise diğer problemler olarak belirtmişlerdir. Katılımcıların en fazla tercih ettiği rekreasyon alanının Suçıktı Mesire Alanı olduğu tespit edilmiştir. Dursunbey ilçesi doğal alanlar açısından yörede önemli bir konumda olmasına rağmen, insanların ziyaret edebileceği rekreasyon alanlarının gerek sayı olarak gerekse kullanım yönüyle birtakım eksikliklerin olması, bu konuda ilgili kurum ve kuruluşlar tarafından yapılacak olan planlama çalışmalarının hız kazanması gereğini ön plana çıkarmaktadır.

Anahtar Kelimeler: Rekreasyon alanları, , kentsel tasarım, serbest zaman faaliyetleri, insan, Dursunbey ilçesi.

\section{Qualitative and Quantitative Analysis of Recreation Areas of Dursunbey District}

\begin{abstract}
Demand of people in order to live natural life is increasing day by day due to the particular causes such as technological advances, industrialization, unplanned urbanization, excessive population growth, intensive work condition. Not only the natural habitats, but also the recreational areas in cities and urban areas meet the needs of people to rest, have fun together and spend time together. In this study, it is aimed to examine the recreational areas in the district of Dursunbey qualitatively and quantitatively.. As a method, a questionnaire was applied to a total of 218 people in Dursunbey district center, 76 of which were women and 142 of which were men. According to the survey results, it was found that $37.6 \%$ of the participants have been visiting the recreation areas with weekly periods and 39\% have been visiting the recreation areas with monthly periods and their reason of visits was the enjoyment in particular. According to the questionnaire, $73.8 \%$ of the participants stated that the number of the recreation areas is scarce. On the other hand, $26.8 \%$ of the respondents stated the noise, $18.9 \%$ stated the security, $5 \%$ stated the air pollution and $43.6 \%$ stated the traffic density as the other problems when evaluating the negativities for the existing recreation areas. It has been determined that the most preferred recreation area by the participants is the Suçıktı recreation area. Despite the fact that the Dursunbey district has a significant place in the region in terms of natural areas, the quantitative and qualitative deficiency of recreational areas that people can visit, is a priority for the prospective sustainable planning studies to be carried out by relevant institutions and organizations.
\end{abstract}

Keywords: Recreation area, urban design, free time activities, human, Dursunbey district. 


\section{Giriş}

Rekreasyon alanları insan hayatında önemli bir yer tutmaktadır. Bütüncül bir bakış ile ele alındığında, rekreasyon alanları sadece bireysel insan hayatı için değil, aynı zamanda bir ülkenin ekonomik, sosyal ve kültürel gelişimi için de oldukça önemlidir. Rekreasyon ve boş zaman kavramı birbirleriyle doğrudan ilişkilidir. Çünkü boş zamanı olan insanlar rekreasyon alanlarından faydalanmaktadır.

Argan'a (2015) göre boş zaman (leisure), genellikle, kişinin çalışma gibi günlük yaşantısını bırakıp, onun yerine oldukça hoşuna giden, eğlenceli etkinliklerle ilgilenmesini içerir. Başka bir deyişle boş zaman kişinin mesleki, ailevi ve toplumsal sorumluluklarını ve yaşamlarını sürdürebilmesi için gerekli olan aktiviteleri yerine getirdikten sonra, kendi iradesiyle yapabileceği bilgi ve becerilerini geliştirme, eğlenme, dinlenme, toplumsal hayata kendi iradesiyle katılma gibi faaliyetlerini ortaya koyabileceği zaman dilimidir (Kurar ve Baltacı, 2015). Güler'e göre, kişinin şahsı adına özgürce kullanma hakkına sahip olduğu, iş ve yaşamla ilgili gerekli sorumluluklarını gerçekleştirdikten sonra artan zaman olarak ifade edilen boş zaman, kişinin bir şey yapmak ya da yapmamak arasında karar verebildiği, yapmak ya da yapmamak istediği şeyleri yine serbestçe belirleyebildiği, ama yapılan işin sorumluluğunu da yüklenebilecek davranışlar gösterebilmesi gereken zaman dilimi şeklinde tanımlanmıştır (Karaküçük, 2014).

Karaküçük'e (1999) göre rekreasyon, bireyin sıkı çalışma koşulları, rutin yaşam biçimi veya olumsuz çevresel etkilerden tehlike altında olan veya negatif etkilenen vücudu ve ruhsal sağlığını muhafaza etmek veya sürdürebilmek için, bireysel doyuma ulaşacak, bütünüyle iş ve gerekli ihtiyaçlar adına belirlenen zaman haricinde kalan özgür ve ilişkili olmayan boş zaman içerisinde, talepler doğrultusunda ve istekli bir şekilde bireysel veya grup halinde belirlenerek yapılan faaliyetlere rekreasyon denir (Koçyiğit ve Yıldız, 2015). Rekreasyon; bireylerin yaşantısına paralel ve yerine getirmekten mutlu olacağı bir faaliyet içerisinde rutin hale gelen ve benzer durumu tekrar edercesine "iş-ev" arasındaki yaşantısını, gerekli durumlardan bağımsız psikolojik olarak rahatlamayıp diğer bireylerle daha güzel vakit geçirerek sosyalleşmesidir (Şahbaz ve Altınay, 2015).

Rekreasyonel faaliyetlerin yapıldığı yerin özelliklerine veya mekanlar arasındaki farklılıklar gözlemlenmesi doğrultusunda oluşturulan sınıflandırmaya göre, "kapalı yer" ve "açık hava" olmak üzere, farklı rekreasyon şekilleri ortaya çıkmaktadır. Kapalı mekân rekreasyonu, yapılar ve tasarlanmış iç mekanlarda yapılan aktiviteler olarak görülmektedir. Açık hava rekreasyonu ise, doğal koşullar altında insanlara daha fazla hareket imkânı sunan ve kapalı olmayan mekanlarda yapılan rekreasyonel etkinliklerinden oluşmaktadır (Müderrisoğlu ve Uzun, 2004).

Açık alan etkinlikleri karada, havada ve su yüzeylerinde gerçekleştirilen etkinlikler olarak tanımlanabilir. Trekking, piknik, dağcılık, doğa gözlemleri, kültürel faaliyetler, doğal alanlarda yapılan eğitim faaliyetleri, yamaç dalışı ve yamaç paraşütü, uçurtma şenlikleri gibi aktiviteler açık alan etkinlikleri kapsamında örnek verilebilecek etkinliklerdir (Ardahan ve Yerlisu, 2011). Açık alan rekreasyonu, doğa içerisindeki bir parça ve faaliyet içerisinde olan katılımcı ile arasında etkileşim ortaya koyabilen ve kişinin bireysel fiziksel ve psikolojik açıdan rahatlaması için yapılan serbest zaman aktiviteleri olarak tanımlanabilir (İbrahim ve Cordes, 2002). Günümüzde açık alan rekreasyon faaliyetlerine ve doğa sporlarına ilginin artması sanayileşme ve kentleşmenin hızlı bir şekilde artmasından kaynaklanmaktadır (Aslan, 1993).

Rekreasyon alanlarının kişisel yararları; insanların kişisel beceri ve yeteneğini geliştirmek, fiziki sağlık gelişimine katkı sağlamak, çalışma başarısının arttırılarak iş verimini sağlamak, sosyal ve yaratıcılığı geliştirerek insanı mutlu etmesidir. Toplumsal yararları ise, toplumsal dayanışmayı sağlayarak demokratik ve sosyal bir toplum yaratmasıdır (Düner, 2016).

Bilim insanları aktif rekreasyon faaliyetlerinin, şiddet ve suç ile negatif bir ilişkisinin olduğunu ortaya koymuşlardır. Bilim insanlarının yaptığı çalışmalarda, rekreasyon için ayrılan mekanların ve bu mekanlarda gerçekleştirilen rekreasyon etkinliklerinin bireyleri rahatlattığı, daha mutlu olmalarını sağladığı, şiddet ve suç oranlarında düşüş olduğu tespit edilmiştir (Tütüncü ve Aydın, 2014).

İnsanların serbest zamanını ne şekilde değerlendireceği konusunda karar vermesini etkileyen birtakım sınırlayıcılar vardır ve bu sınırlayıcıların bir bölümü kişinin özel durumlarından kaynaklanır. Bunlar;

- Gelir durumu

- Meslek ve yaş

- Cinsiyet

- Etkinliğin türü ve mekân seçimi 
- Gelenekler, alışkanlıklar (Yılmaz et al, 2003).

Serbest zamanını değerlendirme konusunda sınırlayıcılar arasında birtakım çevresel faktörler vardır. Bunlar; mevcut rekreasyon olanaklarının çeşitliliği ve hava koşulları, niteliği, maliyeti, ulaşılabilirliği olarak tanımlanabilir (Aydemir, 1998). Rekreasyon alanlarında yapılan faaliyetlerin çeşitliliği bireylerin cinsiyet, yaş, ekonomik ve sosyo-kültürel yapısı gibi etkenlere göre değişiklik göstermektedir (Altunkasa ve Uzun, 1997). Rekreasyon alanlarında kişilerin maddi durumları, tercih ettikleri rekreasyon faaliyetleriyle doğrudan ilişkilidir (Müderrisoğlu, 2002).

\section{Materyal ve Metot}

Dursunbey ilçesi Balıkesir il sınırları içerisinde bulunup ile 74 km uzaklıktadır. 39.58 enlem, 28.62 boylam derecelerinde ve merkez rakımı 644 metredir (Şekil 1). Balıkesir ilinin doğusunda yer alan Dursunbey ilçesi arazi yapısı itibariyle dağlık ve engebeli bir yapıya sahiptir. TÜİK 2017 nüfus verilerine göre ilçe merkez nüfusu 16.567 kişidir (URL 1, 2017).

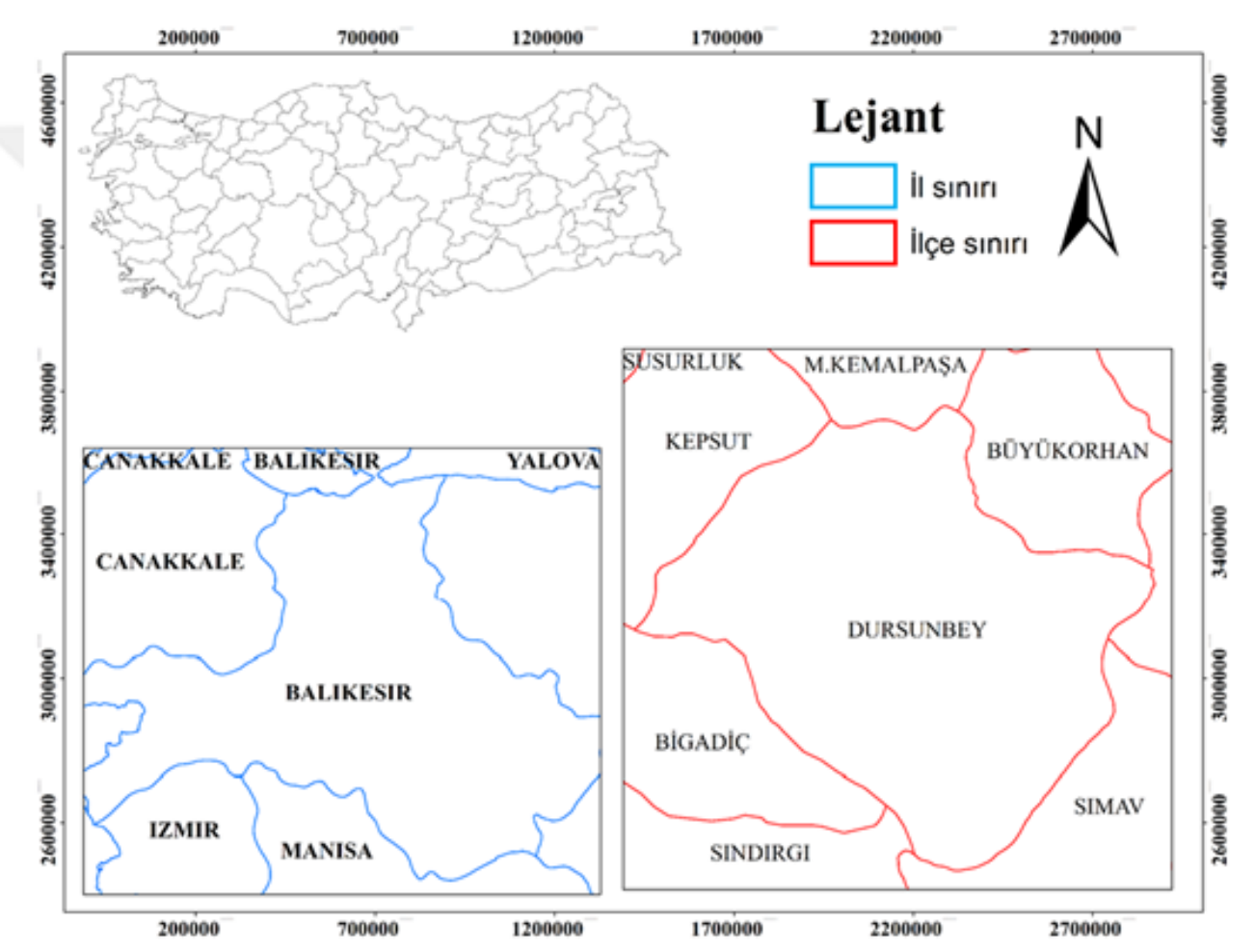

Şekil 1. Çalışma alanına ait yer bulduru haritası

Çalışmaya ilişkin gerekli literatür araştırması, yöntemin ilk aşamasını oluşturmaktadır. İkinci aşamada ise Dursunbey ilçesi merkezinde 76'sı kadın 142'si erkek olmak üzere toplam 218 kişiye anket uygulanmıştır. Anket sonuçları Excel ortamında değerlendirilmiştir.

\section{Bulgular ve Tartışma}

Çalışma kapsamında uygulanan anket, 20-31 Mart 2018 tarihleri arasında Dursunbey ilçesi merkezinde yapılmıştır. Çalışma kapsamında yapılan ankette katılımcılara toplamda 20 soru sorulmuştur. Ankete katılanların 76'sı kadın, 142'si ise erkektir. 11-17 yaş arası katılımcı sayısı 15, 18-25 yaş arası 38, 26-33 yaş arası 63, 34-41 yaş arası 40, 42-49 yaş arası 35, 50 ve üzeri yaş ise 27 kişidir. Katılımcıların 138'i evli 80'ni bekardır. Aynı zamanda 130 kişi çocuk sahibidir. Meslek grubuna göre dağılımları; kamu 113 kişi, özel 49 kişi, ev hanımı 7 kişi ve diğer 49 kişiden oluşmaktadır. Katılımcılardan 26 kişi ilköğretim, 98 kişi orta öğretim, 32 kişi ön lisans, 53 kişi lisans ve 9 kişi yüksek lisans eğitimine sahiptir. Katılımcıların demografik özellikleri Tablo 1'de verilmiştir. 
Tablo 1. Ankete katılan katılımcıların demografik özellikleri

\begin{tabular}{|c|c|c|c|}
\hline \multirow{2}{*}{ Özellikler } & \multirow{2}{*}{ Seçenekler } & \multicolumn{2}{|c|}{ Cinsiyet } \\
\hline & & Kadın & Erkek \\
\hline \multirow{6}{*}{ Yaş } & $11-17$ & 13 & 2 \\
\hline & $18-25$ & 19 & 19 \\
\hline & $26-33$ & 15 & 48 \\
\hline & $34-41$ & 17 & 23 \\
\hline & $42-49$ & 8 & 27 \\
\hline & 50 ve üzeri & 4 & 23 \\
\hline \multirow{2}{*}{ Medeni durum } & Evli & 33 & 105 \\
\hline & Bekar & 43 & 37 \\
\hline \multirow{2}{*}{ Çocuk durumu } & Var & 33 & 97 \\
\hline & Yok & 43 & 45 \\
\hline \multirow{4}{*}{ Meslek } & Kamu & 25 & 88 \\
\hline & Özel & 14 & 35 \\
\hline & Ev hanımı & 7 & 0 \\
\hline & Diğger & 30 & 19 \\
\hline \multirow{5}{*}{$\begin{array}{l}\text { Eğitim } \\
\text { durumu }\end{array}$} & İlköğretim & 8 & 18 \\
\hline & Ortaöğretim & 47 & 51 \\
\hline & ÖnLisans & 6 & 26 \\
\hline & Lisans & 13 & 40 \\
\hline & Y. Lisans & 2 & 7 \\
\hline
\end{tabular}

Dursunbey'de yaşayan halka uygulanan anketin çalışmasının ilk 16 sorusu evet ve hayır seçeneklerinden oluşmaktadır. Sorular ve verilen yanıtlar sayı ve yüzde olarak Tablo 2' de verilmiştir.

Tablo 2. Anketin ilk 16 sorusuna verilen cevaplar

\begin{tabular}{|c|c|c|c|c|c|c|}
\hline \multirow{2}{*}{ Soru } & \multicolumn{2}{|c|}{ Evet $(\%)$} & \multicolumn{2}{|c|}{ Hayır (\%) } & \multicolumn{2}{|c|}{ Toplam (\%) } \\
\hline & Kadın & Erkek & Kadın & Erkek & Evet & Hayır \\
\hline 1-Boş zamanlarınızda rekreasyon alanlarına gider misiniz? & 100 & 100 & 0 & 0 & 100 & 0 \\
\hline $\begin{array}{l}\text { 2-Rekreasyon alanlarının sizin hayatınıza katkı sağladığını } \\
\text { düşünüyor musunuz? }\end{array}$ & 75 & 77 & 25 & 23 & 77 & 23 \\
\hline $\begin{array}{l}\text { 3-Rekreasyon alanları ailenizle akrabalarınızla komşunuzla ve } \\
\text { tüm yakınlarınızla ilişkilerinizi geliştirdiğini düşünüyor } \\
\text { musunuz? }\end{array}$ & 86 & 71 & 14 & 29 & 76 & 24 \\
\hline $\begin{array}{l}\text { 4-Rekreasyon alanlarındaki ücretli aktivitelerin size göre } \\
\text { pahalı olduğunu düşünüyor musunuz? }\end{array}$ & 55 & 57 & 45 & 43 & 56 & 44 \\
\hline $\begin{array}{l}\text { 5-Gittiğiniz rekreasyon alanlarını niceliksel (Sayı) açıdan } \\
\text { eksik buluyor musunuz? }\end{array}$ & 78 & 72 & 22 & 28 & 74 & 26 \\
\hline 6-Rekreasyon alanlarındaki spor alanları yeterli mi? & 25 & 25 & 75 & 75 & 25 & 75 \\
\hline 7-Rekreasyon alanlarındaki çocuk oyun alanları yeterli mi? & 32 & 65 & 68 & 35 & 53 & 47 \\
\hline 8-Rekreasyon alanlarındaki sosyal faaliyet alanları yeterli mi? & 16 & 14 & 84 & 86 & 15 & 85 \\
\hline 9-Rekreasyon alanlarındaki piknik alanları yeterli mi? & 41 & 37 & 59 & 63 & 39 & 61 \\
\hline
\end{tabular}


10-Rekreasyon alanlarındaki restoranlar, kafeler yeterli mi?

$\begin{array}{llllll}21 & 27 & 79 & 73 & 25 & 75 \\ 67 & 69 & 33 & 38 & 68 & 36 \\ 43 & 42 & 57 & 58 & 43 & 57 \\ 37 & 25 & 63 & 75 & 29 & 71 \\ 38 & 37 & 62 & 63 & 37 & 63 \\ 84 & 62 & 16 & 38 & 70 & 30 \\ 62 & 44 & 38 & 56 & 50 & 50\end{array}$

11-Rekreasyon alanlarına ulaşımı rahat sağlayabiliyor musunuz?

12-Rekreasyon alanlarına ulaşımı sağlayan araçlar yeterli mi?

13-Dursunbey'deki rekreasyon alanları her mevsim gitmek için uygun mu?

14-Rekreasyon alanlarının temizliğini yeterli buluyor musunuz?

15-Rekreasyon alanlarının Dursunbey ilçesinin gelişiminde katkısı olduğunu düşünüyor musunuz?

16-Rekreasyon alanlarında hali hazırda bulunmayan fakat bulunmasını istediğiniz eksiklikler var mı?

Anketin 17, 18, 19 ve 20. sorularına verilen cevapların yüzdeleri sırasıyla Tablo 3, 4, 5 ve 6'da verilmiştir.

Tablo 3. Anketin 17. sorusuna (Rekreasyon alanlarına hangi sıklıkta gidersiniz?) verilen cevaplar (\%).

\begin{tabular}{lcccc}
\hline & Günde & Haftada & Ayda & Yılda \\
\hline Kadın & 2 & 36 & 50 & 12 \\
Erkek & 4 & 41 & 35 & 20 \\
Toplam & 3 & 39 & 41 & 17 \\
\hline
\end{tabular}

Tablo 4. Anketin 18. sorusuna (Dursunbey ilçesinde bulunan rekreasyon alanlarından en çok hangisini tercih ediyorsunuz?) verilen cevaplar (\%). (Katılımcılara 18. soruda birden fazla seçenek seçme hakkı sunulmuştur)

\begin{tabular}{lcccccc}
\hline & Suçıktı & Saz & Pembe Köşk & Hıdırlık & Düğüncüler & Çınarlıpınar \\
\hline Kadın & 87 & 32 & 9 & 9 & 4 & 3 \\
Erkek & 67 & 13 & 13 & 9 & 8 & 11 \\
Toplam & 64 & 20 & 11 & 9 & 6 & 8 \\
\hline
\end{tabular}

Tablo 5. Anketin 19. sorusuna(Rekreasyon alanlarına en çok ne amaçla gider siniz?) verilen cevaplar (\%).(Katılımcılara 19. soruda birden fazla seçenek seçme hakkı sunulmuştur)

\begin{tabular}{lccc}
\hline & Kadın & Erkek & Toplam \\
\hline Eğlenmek & 53 & 30 & 38 \\
Spor yapmak & 22 & 8 & 13 \\
Çocuklarla birlikte zaman geçirmek & 26 & 35 & 32 \\
Piknik yapmak & 21 & 26 & 24 \\
Sosyal aktiviteler & 8 & 9 & 9 \\
Dinlenmek & 22 & 15 & 17 \\
Diğerleri & 1 & 8 & 6 \\
\hline
\end{tabular}

Çalışmada katılımcılara anket sorularının dışında Dursunbey’de bulunan rekreasyon alanlarının var olan eksikliklerini ve rekreasyon alanlarına yönelik istekleri sorulmuştur. Verilen yanıtlardan yola çıkarak özellikle rekreasyon alanlarının daha temiz olması (\%12), farklı sosyal aktivite alanlarının oluşturulması (\%13), spor alanlarının arttırılması (\%11), yeni işletme mekanlarının açılması (\%15) gibi konular katılımcıların öncelikli istek ve önerileri olmuştur. Her bir istek ve öneri tek tek değerlendirilerek Tablo 7'de gösterilmiştir. 
Tablo 6. Anketin 20. sorusuna (Rekreasyon alanlarında aşağıdaki olumsuz etkilerden hangisiyle karşı karşıya kalıyorsunuz?) verilen cevaplar (\%).(Katılımcılara 20. soruda birden fazla seçenek seçme hakkı sunulmuştur)

\begin{tabular}{lccc}
\hline & Kadın & Erkek & Toplam \\
\hline Hava kirliliği & 8 & 4 & 6 \\
Gürültü & 28 & 28 & 28 \\
Trafik yoğunluğu & 3 & 7 & 6 \\
Güvenlik problemleri & 26 & 16 & 20 \\
Diğerleri (temizlik vb.) & 53 & 42 & 45 \\
\hline
\end{tabular}

Tablo 7. Ankete katılan kişilerin rekreasyon alanında tespit ettikleri eksiklikler ve istekleri

\begin{tabular}{|c|c|c|c|c|}
\hline $\begin{array}{l}\text { Ankete Katılan Kişilerin Rekreasyon Alanında Tespit Ettikleri } \\
\text { Eksiklikler ve İstekleri }\end{array}$ & Kadın & Erkek & Toplam & Yüzde\% \\
\hline Temizlik & 6 & 8 & 14 & 12 \\
\hline Ulaşım & 4 & 3 & 7 & 6 \\
\hline Farklı dosyal aktivite & 11 & 5 & 16 & 13 \\
\hline Çocuklar için oyun alani & 1 & 5 & 6 & 5 \\
\hline Kapalı alan & 4 & 3 & 7 & 6 \\
\hline Mangal (SuÇıktı) & 2 & 3 & 5 & 4 \\
\hline Engelli çıkış alanı & 0 & 1 & 1 & 1 \\
\hline Spor alanı (Saz) & 8 & 5 & 13 & 11 \\
\hline Masa & 2 & 7 & 9 & 8 \\
\hline Saz ile Suçıktı arasındaki yolun genişletilmesi ve güzelleştirilmesi & 4 & 1 & 5 & 4 \\
\hline Fiyatlar pahalı & 0 & 2 & 2 & 2 \\
\hline Çöp konteyneri & 0 & 2 & 2 & 2 \\
\hline Yeni işletme mekanları & 15 & 3 & 18 & 15 \\
\hline Rekreasyon alanlarının doğallığının korunması & 0 & 1 & 1 & 1 \\
\hline Düğün zamanı ses (yüksek) & 1 & 1 & 2 & 2 \\
\hline Saz rekreasyon alanının geliştirilmesi & 0 & 1 & 1 & 1 \\
\hline Aydinlatma & 0 & 1 & 1 & 1 \\
\hline Bank & 3 & 1 & 4 & 3 \\
\hline Restorasyon çalışmaları (Düğüncüler) & 2 & 0 & 2 & 2 \\
\hline Tuvalet & 2 & 0 & 2 & 2 \\
\hline Mekanlarda yöresel yemek & 1 & 0 & 1 & 1 \\
\hline
\end{tabular}

\section{Sonuç ve Öneriler}

Dursunbey ilçesi doğal güzellikleri bakımından oldukça zengin bir coğrafi yapıya sahiptir. Zengin bitki türleri, yaban hayatı, tarım ve orman varlığı ilçenin en önemli özelliklerini oluşturmaktadır. Özellikle kırsal alanlarda yaşayan halkın kültürel değerlerini oluşturan geleneklerini korumaya çalışması ilçenin doğal yapısının bozulmamasında önemli bir etken olmuştur.

Dursunbey’de yaşayan halkın boş vakitlerinde aileleriyle birlikte eğlenceli ve verimli vakit geçirmelerini sağlayan rekreasyon alanlarının niteliksel ve niceliksel açıdan yeterli olması oldukça önemlidir. Çünkü çalışma sonucunda katılımcıların tamamı boş zamanlarında rekreasyon alanlarına gittiklerini ifade etmiştir. Ayrıca rekreasyon alanlarının gerek aileleriyle gerekse komşu ve akrabalarıyla olan ilişkilerini olumlu anlamda etkilediğini belirtmişlerdir. Halkın rekreasyon alanlarına gitmelerinin en önemli sebebi öncelikle eğlenmek ve 
çocuklarıyla birlikte güzel vakit geçirmek olduğu sonucu çıkmıştır. Anket sonuçlarına göre Dursunbey ilçesinde halkın en çok gittiği rekreasyon alanı Suçıktı Mesire Alanı'dır.

Katılımcılar niceliksel açıdan rekreasyon alanlarının eksik olduğu özellikle spor, sosyal faaliyet ve piknik alanlarının aynı zamanda var olan rekreasyon alanlarında restoran ve kafe gibi mekanların sayıca yetersiz olduğunu ifade etmişlerdir. Katılımcılar gitmekte oldukları rekreasyon alanlarının her mevsim kullanımı için uygun olmadığını özellikle kış aylarında kapalı mekanların az ve niteliksel açıdan yetersiz olduğu bununla birlikte rekreasyon alanlarında en büyük sorunların sırasıyla temizlik, gürültü ve güvenlik olduğunu belirtmişlerdir.

Anket sonuçlarından yola çıkarak Dursunbey İlçesinin rekreasyon faaliyetlerinin gelişimi için belirli öneriler getirilmiştir. Bu öneriler;

- Rekreasyon alanlarının sayısının arttırılması, halka farklı rekreasyon alan seçeneklerinin sunulması hem sosyal ilişkilerin gelişmesini hem de ekonomik ve kültürel açıdan Dursunbey ilçesine önemli katk1 sunacaktır.

- Spor alanı ve aletlerinin sayısı arttırılmalıdır. Özellikle üniversite öğrencilerinin yararlanabileceği spor alanları oluşturulabilir. Tek başına bir mekân olarak değil aynı zamanda trekking ve dağcılık gibi aktivitelerle spor faaliyetleri oluşturulabilir.

- Müzik, dans, resim vb. sanatsal etkinliklerin ve kursların olabileceği sosyal ve kültürel faaliyet alanları oluşturmak rekreasyon alanlarına ilgiyi arttıracaktır.

- Rekreasyon alanlarındaki kafeterya ve restoranların hem sayısının arttırılması hem de her mevsim kullanabilecek şekilde planlanması gerekmektedir. $\mathrm{Bu}$ bağlamda yörenin doğal yapısına uygun tasarımlar yapılabilir.

- Belediye ve emniyet güçlerinin gerekli önlemleri alarak rekreasyon alanlarındaki temizlik, gürültü ve güvenlik problemleri giderilebilir.

- Engelsiz tasarım yaklaşımıyla tüm engel gruplarının rahatça gidebilecekleri rekreasyon alanları planlanmalıdır. Özellikle çocuk oyun alanlarında ve spor alanlarında engelli bireylerin de kullanabileceği oyun elemanları ve spor aletleri yapılabilir.

- Planlanacak ve planlanması düşünülen tüm rekreasyon alanların doğal yapıya ve ekosisteme zarar vermemesine dikkat edilmelidir. Konusunda uzman kişilerce koruma ve kullanım dengesinin oluşturulmasında gerekli planlamalar yapılmalıdır.

\section{Kaynaklar}

1. Kurar İ, Baltacı, F (2015). Halkın Boş Zaman Değerlendirme Alışkanlıkları: Alanya Örneği. International Journal of Science Culture and Sport, Special Issue 2, 4.

2. Karaküçük, S (2014). Rekreasyon: Boş Zamanları Değerlendirme, 33-34.

3. Koçyiğit M, Yıldız M (2015). Yerel Yönetimlerde Rekreasyon Uygulamaları: Konya Örneği, International Journal of Science Culture and Sport, Special Issue 2, 212-213.

4. Şahbaz RP, Altınay M (2015). Türkiye'deki Milli Parkların Rekreasyon Faaliyetleri Açısından Değerlendirilmesi, Journal of Tourism and Gastronomy Studies, 3.3, 125-135.

5. Müderrisoğlu H, Uzun S (2004).Abant İzzet Baysal Üniversitesi Orman Fakültesi Öğrencilerinin Rekreasyonel Eğilimleri. Süleyman Demirel Üniversitesi Orman Fakültesi Dergisi, Seri: A, Sayı: 2, 108121.

6. Ardahan F, Yerlisu L. T(2011). Açık Alan Rekreasyonu: Bisiklet Kullanıcıları ve Yürüyüşçülerin Doğa Sporu Yapma Nedenleri ve Elde Ettikleri Faydalar, Uluslararası İnsan Bilimleri Dergisi, Cilt:8, Sayı:1.

7. İbrahim H, Cordes KA (2002). Outdoor Recreation, Enrichment for a Life time. Second Edition, Sagamore Publishing, Il.

8. Aslan Z (1993).Sanayileşme ve Kentleşmenin Doğada Rekreasyon Faaliyetlerine Duyulan Gereksinimi Arttırıcı etkisi. Ekoloji ve Çevre Dergisi, 2(8): 22-24. 
9. Koç N (1991).Rekreasyon Ders Notları, Ankara Üniversitesi Ziraat Fakültesi Peyzaj Mimarlığı Bölümü, Ankara.

10. Koçan N (2012).Kızılcahamam-Çamlıdere Jeoparkı'nda Kırsal Peyzaj ve Rekreasyon Planlama. Erciyes Üniversitesi Fen Bilimleri Enstitüsü Dergisi, 28(1): 38-46.

11. Can E (2015). Boş Zaman, Rekreasyon ve Etkinlik Turizmi İlişkisi. İstanbul Sosyal Bilimler Dergisi, 10 , $1-17$.

12. Düner M (2016).Erzincan Kentinin Rekreasyon Alanları. Yüksek Lisans Tezi, Erzincan Üniversitesi, Sosyal Bilimler Enstitüsü, Erzincan.

13. Tütüncü Ö, Aydın İ (2014). Toplum ve Açık Hava Rekreasyon Faaliyetleri: ABD Örneği. Anatolia: Turizm Araştırmaları Dergisi, 25.1, 118-120.

14. Yılmaz H, Yılmaz S, Yıldız ND (2003).Kars Kent Halkının Rekreasyonel Talep ve Eğilimlerinin Belirlenmesi. Atatürk Üniversitesi Ziraat Fakültesi Dergisi, 34(4).

15. Aydemir S (1998).Kentsel Donatılar Açık Alanlar ve Rekreasyon Kentsel Yeşil Alanlar, Kentsel Alanların Planlanması ve Tasarımı. Karadeniz Teknik Üniversitesi, Mimarlık Fakültesi Ders Notları: 54, Trabzon.

16. Altunkasa F, Uzun G (1997).Rekreasyonel Planlamada Arz ve Talep. Çukurova Üniversitesi Ziraat Fakültesi. Yayın No: 6, Adana.

17. Müderrisoğlu H (2002). Açık Hava Rekreasyonunda Taşıma Kapasiteleri Rekreasyonel Kullanım İlişkilerinin İncelenmesi. İstanbul Üniversitesi Orman Fakültesi. Doktora Tezi, İstanbul.

18. URL-1 (2018). http://www.tuik.gov.tr/PreTablo.do?alt_id=1059”. 